\title{
Developing Novel Antiepileptic Drugs: Characterization of NAX 5055, a Systemically-Active Galanin Analog, in Epilepsy Models
}

\author{
H. Steve White, ${ }^{*}$ Erika A. Scholl, ${ }^{\ddagger}$ Brian D. Klein, ${ }^{\ddagger}$ Sean P. Flynn, ${ }^{*}$ Timothy H. Pruess, ${ }^{*}$ \\ Brad R. Green, ${ }^{\dagger}$ Liuyin Zhang, ${ }^{\dagger}$ and Grzegorz Bulaj ${ }^{\dagger}$ \\ *Department of Pharmacology and Toxicology, 'Department of Medicinal Chemistry, College of Pharmacy, University of Utah, \\ Salt Lake City, Utah 84108, ${ }^{\ddagger}$ NeuroAdjuvants, Inc., Salt Lake City, Utah, 84108
}

\begin{abstract}
Summary: The endogenous neuropeptide galanin and its associated receptors galanin receptor 1 and galanin receptor 2 are highly localized in brain limbic structures and play an important role in the control of seizures in animal epilepsy models. As such, galanin receptors provide an attractive target for the development of novel anticonvulsant drugs. Our efforts to engineer galanin analogs that can penetrate the blood-brain-barrier and suppress seizures, yielded NAX 5055 (Gal-B2), a systemically-active analog that maintains low nanomolar affinity for galanin receptors and displays a potent anticonvulsant activity. In this report, we show that NAX 5055 is active in three models of epilepsy: 1) the Frings audiogenic seizuresusceptible mouse, 2) the mouse corneal kindling model of partial epilepsy, and 3) the $6 \mathrm{~Hz}$ model of pharmacoresistant
\end{abstract}

epilepsy. NAX 5055 was not active in the traditional maximal electroshock and subcutaneous pentylenetetrazol seizure models. Unlike most antiepileptic drugs, NAX 5055 showed high potency in the $6 \mathrm{~Hz}$ model of epilepsy across all three different stimulation currents; i.e., 22, 32 and $44 \mathrm{~mA}$, suggesting a potential use in the treatment of pharmacoresistant epilepsy. Furthermore, NAX 5055 was found to be biologically active after intravenous, intraperitoneal, and subcutaneous administration, and efficacy was associated with a linear pharmacokinetic profile. The results of the present investigation suggest that NAX 5055 is a first-in-class neurotherapeutic for the treatment of epilepsy in patients refractory to currently approved antiepileptic drugs. Key Words: Neuropeptide, anticonvulsant drug, audiogenic seizures, $6 \mathrm{~Hz}$ seizure, corneal kindled mouse.

\section{INTRODUCTION}

It is estimated that there are 50 to 60 million people with epilepsy worldwide. Epilepsy affects approximately 3 million people in the United States alone. Each year, 125,000 new cases are diagnosed. Unfortunately, only $70 \%$ of patients are effectively treated with currently available antiepileptic drugs (AEDs). For a substantial number of patients with epilepsy, the currently available therapies are often not effective in controlling their symptoms. As such, there is a substantial need for more effective therapies.

Neuropeptides are potent modulators of neuronal excitability. ${ }^{1,2}$ Under ambient conditions, peptides are "silent" and exert little effect on normal neurotransmission. However, under conditions of excessively high neuronal

Address correspondence and reprint requests to: H. Steve White, Ph.D., Anticonvulsant Drug Development Program, Department of Pharmacology and Toxicology, 417 Wakara Way, Suite 3211, Salt Lake City, Utah 84108. E-mail: swhite@hsc.utah.edu. firing (i.e., epileptic seizures), neuropeptides are released and exert a modulatory effect on neurotransmission. Unlike small molecule neurotransmitters, neuropeptides are released distal to the synaptic cleft and their action is limited by diffusion and enzymatic degradation, instead of being eliminated by reuptake or rapid degradation. Unlike classical neurotransmitters, the action of neuropeptides is slow, sustained, and can extend beyond the synaptic region. ${ }^{3}$ One such neuropeptide is galanin and it has been implicated in such diverse behaviors as sleep, feeding, reproduction, nociception, and cognition. Galanin is found along with many neurotransmitters, including glutamate, gamma-aminobutyric acid (GABA), acetylcholine, norepinephrine, serotonin, dopamine and histamine, suggesting it has many roles in the brain. ${ }^{4,5}$ Galanin, which can be found both centrally and peripherally, is highly expressed along with the galanin receptor 1 (GalR1) in the hippocampus, a plastic structure highly susceptible to seizure activity. 
There have been numerous studies linking galanin to seizure activity. Expression levels of galanin and its receptors change in response to, or as a result of, seizures. ${ }^{6}$ For example, galanin levels and galanin receptor 2 (GalR2) are decreased after status epilepticus. Since the work of Mazarati and coworkers, ${ }^{7}$ there has been increasing evidence that galanin is a potent anticonvulsant peptide. Previous investigations have demonstrated that galanin and galanin agonists, when delivered directly to the brain, possess anticonvulsant properties. ${ }^{8,9}$ Moreover, the acute administration of galanin receptor agonists or virus-mediated overexpression of galanin in the hippocampus has been found to inhibit limbic status epilepticus, pentylenetetrazol-induced, and picrotoxin-induced seizures in rats and mice. ${ }^{7,8,10}$ Furthermore, several reports have suggested that centrally administered galanin may modify the damage associated with limbic seizures and delay or prevent the development of epilepsy (i.e., disease modifying). Kokaia et al. ${ }^{11}$ reported delayed kindling in galanin peptide overexpressing mice. Furthermore, results from studies with GalR1 knockout mice and rats treated with antisense GalR2 oligonucleotides suggests that galanin exerts its anticonvulsant effect through an action at both GalR1 and GalR2. ${ }^{12,13}$

Previous attempts to pharmacologically target the galanin system have been plagued by the finding that peptides are generally not metabolically stable and do not readily penetrate the blood-brain-barrier (BBB). Two galaninbased agonists, i.e., galmic and galnon, that possess anticonvulsant activity have been reported in the literature. ${ }^{14,15}$ However, these compounds show little receptor subtype specificity (2- to 3-fold difference in affinity for GalR1 and GalR2), and they have a 10,000 - to 100,000 -fold lower affinity for galanin receptors relative to the native peptide (FIG. 1). Furthermore, significant off-target activities have been described for both galmic and galnon. ${ }^{16}$

In the present investigation we describe the anticonvulsant actions and pharmacological profile of the novel BBB permeable galanin analog NAX 5055 (Gal-B2) which is bioavailable, metabolically stable, and retains nanomolar affinity and selectivity for galanin receptors. ${ }^{17}$ Previously published results from our laboratory have described in detail the physicochemical properties of this and other galanin analogs. Here we describe the activity of NAX 5055 in various animal seizure and epilepsy models, and we discuss its pharmacokinetic profile and systemic bioavailability. In addition, our results demonstrate that the anticonvulsant activity of this modified peptide is specific for the intact structure of NAX 5055.

\section{MATERIALS AND METHODS}

\section{Peptide synthesis}

NAX 5055 and two galanin analogs (a truncated and a scrambled peptide) were chemically synthesized using identical methods as previously described. ${ }^{17}$ Briefly, the peptides were assembled on solid support using the Fmoc protocol and an automated peptide synthesizer. The analogs were cleaved from the resin by a treatment with reagent $\mathrm{K}$ and purified using reverse-phase high performance liquid chromatography (HPLC) separations. Chemical identities of the analogs were confirmed by mass spectroscopy analyses.

\section{Animals and test substances}

Male albino CF-1 mice (18 to $25 \mathrm{~g}$; Charles River, Portage, MI) and male and female Frings audiogenic seizure (AGS)-susceptible mice (20 to $30 \mathrm{~g}$; obtained from an in-house colony at the University of Utah) were used as experimental animals. All animals were allowed free access to both food (LabDiet, Richmond, IN) and water except when they were removed from their cages for the experimental procedure. All mice were housed, fed, and handled in a manner consistent with the recommendations in the National Research Council Publication, "Guide for the Care and Use of Laboratory Animals." No insecticides capable of altering hepatic drug metabolism enzymes were used in the animal facilities. Except for corneal kindling studies, animals were used once. All animals were euthanized in accordance with the Institute of Laboratory Resources policies on the humane care of laboratory animals.

NAX 5055 was administered in $0.9 \%$ saline intravenously (i.v.), intraperitoneally (i.p.), subcutaneously (s.c.), or orally (p.o.) in a volume of $0.01 \mathrm{~mL} / \mathrm{g}$ body weight.

\section{Anticonvulsant tests}

The anticonvulsant activity of NAX 5055 was established by both electrical and chemical tests. The electrical tests used were the maximal electroshock seizure, the $6 \mathrm{~Hz}$ psychomotor seizure, and the corneal kindled mouse. ${ }^{18-20}$ The chemical tests included the s.c. pentylenetetrazol (PTZ) seizure. ${ }^{18}$

Maximal electroshock and $6 \mathrm{~Hz}$ tests. For the maximal electroshock and $6 \mathrm{~Hz}$ tests, a drop of anesthetic/ electrolyte solution $(0.5 \%$ tetracaine hydrochloride in $0.9 \%$ saline) was applied to the eyes of each animal prior to placement of the corneal electrodes. The electrical stimulus in the maximal electroshock test was $50 \mathrm{~mA}, 60$ $\mathrm{Hz}$ delivered for $0.2 \mathrm{sec}$ by an apparatus similar to that originally described by Woodbury and Davenport. ${ }^{21}$ Elimination of the hind leg tonic extensor component of the seizure was used as the endpoint.

The ability of the test substance to prevent seizures induced by $6 \mathrm{~Hz}$ corneal stimulation $(6 \mathrm{~Hz}, 0.2 \mathrm{msec}$ rectangular pulse width, $3 \mathrm{sec}$ duration) was evaluated at convulsive currents (CC) of 22,32 , and $44 \mathrm{~mA}$. The current was delivered with a Grass S48 stimulator (Grass Technologies, West Warwick, RI). Six Hz seizures are characterized by a minimal clonic phase that is followed by stereotyped automatistic behaviors, originally described as being similar to the aura of human patients 
Table 1. Anticonvulsant Profile of NAX 5055

\begin{tabular}{lcr}
\hline Seizure Model & $\begin{array}{c}\mathrm{ED}_{50} \\
\text { (mg/kg i.p.) }\end{array}$ & $\begin{array}{c}\text { Protective } \\
\text { Index }^{*}\end{array}$ \\
\hline Corneal kindling & 0.65 & $\sim 30$ \\
Audiogenic seizures & 3.2 & $\sim 7$ \\
Maximal electroshock & Inactive at $20 \mathrm{mg} / \mathrm{kg}$ & $<1$ \\
Pentylenetetrazol, s.c. & $25 \%$ at $20 \mathrm{mg} / \mathrm{kg}$ & $<1$ \\
\hline
\end{tabular}

s.c. $=$ subcutaneous injection.

*Toxic dose $50(21 \mathrm{mg} / \mathrm{kg}) / \mathrm{ED}_{50}$.

with partial seizures. ${ }^{19,22}$ Animals not displaying this behavior were considered protected.

Corneal kindling. NAX 5055 was evaluated for its ability to block the fully expressed corneal kindled seizure. Individual mice were corneal kindled according to the procedures established by Matagne and Klitgaard. ${ }^{23}$ Briefly, each mouse received a twice daily corneal stimulation of $3 \mathrm{~mA}$ for $3 \mathrm{~s}$ Monday through Friday. Prior to each of the stimulations, a drop of $0.5 \%$ tetracaine was applied to the cornea of each mouse. The kindling procedure was continued until each mouse displayed at least five consecutive secondarily generalized seizures (i.e., stage 4 to 5 seizures according to the Racine scale). ${ }^{24}$ On the day of the experiment, fully kindled mice were treated i.p. with NAX 5055. One h after NAX 5055 administration, the mice were challenged with the same current stimulus used to kindle them (i.e., $3 \mathrm{~mA}$ for 3 sec). Mice not displaying a prototypical seizure were considered protected.

Pentylenetetrazol (PTZ)-induced seizures. NAX 5055 was evaluated for its ability to block a minimal 3-s episode of a clonic seizure induced by $85 \mathrm{mg} / \mathrm{kg}$ PTZ (dissolved in $0.9 \%$ saline) administered s.c. into a loose fold on the back of the neck. Animals were observed for at least $30 \mathrm{~min}$ for the presence or absence of a seizure.

Audiogenic seizures. NAX 5055 was tested for its ability to block AGS in the Frings AGS-susceptible mouse after i.p. administration. At the previously determined time-to-peak effect (TPE), individual male and female Frings mice were placed into a plastic cylinder (diameter, $15 \mathrm{~cm}$; height, $18 \mathrm{~cm}$ ) fitted with an audio transducer (Model AS-ZC; FET Research and Development, Salt Lake City, UT) and exposed to a sound stim-<smiles>C=CCCCCCCCCCCCCC(=O)NCCCC</smiles>

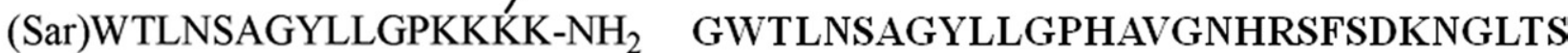

\author{
$\underline{\mathrm{NAX} 5055(\mathrm{Gal} \mathrm{B2})^{\mathrm{a}}}$ \\ hGalR1 $=3.5 \mathrm{nM}$ \\ hGalR2 $=51.5 \mathrm{nM}$
}

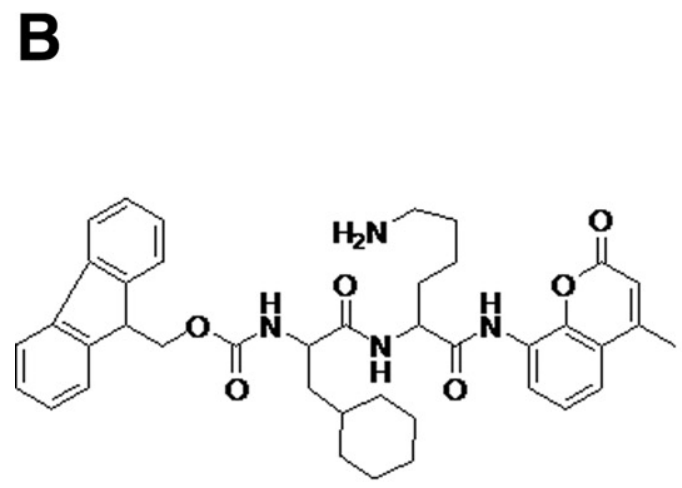

$$
\begin{aligned}
& \frac{\text { Galnon }^{\mathrm{b}}}{\mathrm{hGalR}^{2}}=12 \mu \mathrm{M} \\
& \text { hGalR2 }=24 \mu \mathrm{M} \\
& \text { Non-specific }
\end{aligned}
$$

\author{
Galanin $^{\text {b }}$ \\ hGalR1 $=0.4 \mathrm{nM}$ \\ hGalR2 $=2.3 \mathrm{nM}$
}

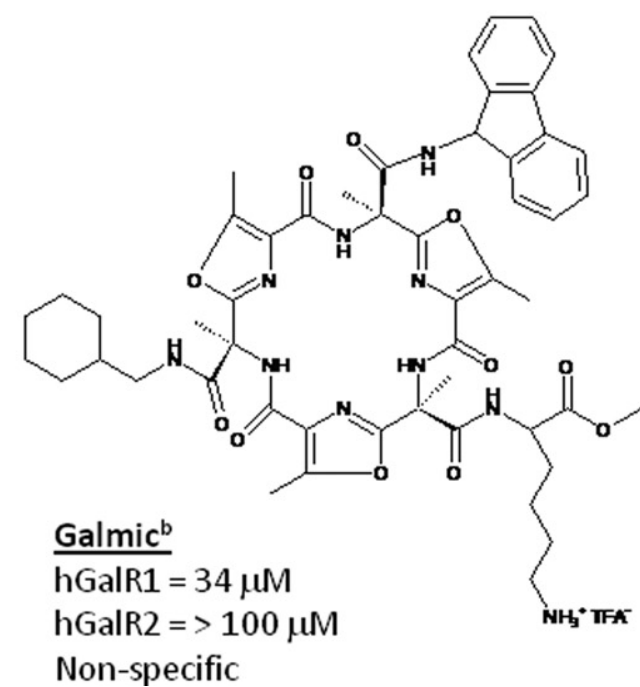

FIG. 1. Structures of selected galanin ligands and their affinities to the human (h)-galanin receptor 1 and h-galanin receptor 2 receptors.

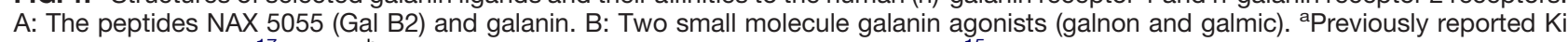
values in Bulaj et al., ${ }^{17}$ 2008.; ${ }^{b}$ Previously reported Kd values in Lundstrom et al., ${ }^{15} 2005$. 


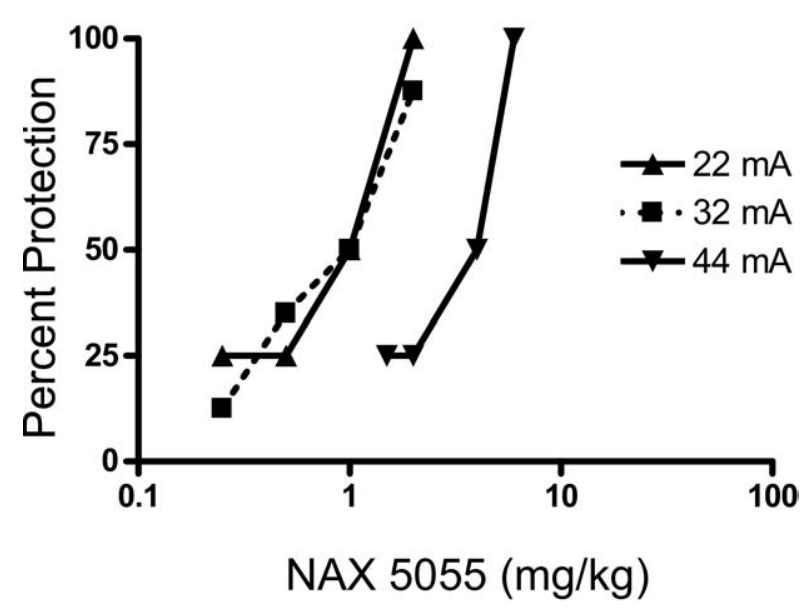

FIG. 2. NAX 5055 maintains potent anticonvulsant activity in the mouse $6 \mathrm{~Hz}$ seizure model with increasing stimulation intensities (22 mA, $32 \mathrm{~mA}$, and $44 \mathrm{~mA}$ ). Bolus injections of NAX 5055 were administered intraperitoneally and dose-response data were generated at the $1 \mathrm{~h}$ time point (time-to-peak effect). Based on these results, $\mathrm{ED}_{50}$ values were calculated as $0.7 \mathrm{mg} / \mathrm{kg}$ for 22 $\mathrm{mA}, 0.8 \mathrm{~mA}$ for $32 \mathrm{~mA}$, and $2.9 \mathrm{mg} / \mathrm{kg}$ for $44 \mathrm{~mA}$ stimulations.

ulus of 110 decibels $(11 \mathrm{KHz})$ delivered for $20 \mathrm{~s}$. A sound-induced AGS is characterized by wild running followed by loss of righting reflex with forelimb and hind limb tonic extension. Mice not displaying hind limb tonic extension were considered protected.

\section{Minimal toxicity tests}

Minimal toxicity was identified in mice by the rotorod procedure. ${ }^{25}$ When a mouse is placed on a 1 -inch knurled rod that rotates at a speed of $6 \mathrm{rpm}$, the animal can maintain its equilibrium for long periods of time. Mice were considered toxic if they fell off this rotating rod three times during a 1-min period. In addition, individual mice were observed for the presence or absence of ataxia, abnormal gait, somnolence, and other signs of acute toxicity. Also, the effect of NAX 5055 on core body temperature was evaluated at various times after i.p. administration of $4 \mathrm{mg} / \mathrm{kg}$.

\section{Determination of median effective dose $\left(E D_{50}\right)$ or toxic dose $\left(\mathrm{TD}_{\mathbf{5 0}}\right)$}

All quantitative in vivo anticonvulsant/toxicity studies were conducted at the time-to-peak effect after i.v., i.p., s.c., and p.o. administration. Groups of at least eight mice were tested with various doses of NAX 5055 until at least two points were established between the limits of $100 \%$ protection or maximal toxicity and $0 \%$ protection or minimal toxicity. The dose of NAX 5055 required to produce the desired endpoint in $50 \%$ of animals $\left(\mathrm{ED}_{50}\right)$ or toxic dose 50 and the $95 \%$ confidence intervals were then calculated by a computer program based on the method described by Finney. ${ }^{26}$

\section{Pharmacokinetics}

To determine the plasma levels of NAX 5055, trunk blood was collected at appropriate time points into hep- arin-coated tubes and centrifuged for $3 \mathrm{~min}$ at 5,000 rpm. Plasma samples were then collected, immediately frozen on dry ice and stored in a $-80^{\circ} \mathrm{C}$ freezer. Prior to the liquid chromatography/mass spectrometry ( $\mathrm{LC} /$ MS) analysis, $50 \mu \mathrm{L}$ of plasma samples were transferred to 96 -well plates, diluted with $50 \mu \mathrm{L}$ of $5 \%$ formic acid in water, mixed by vortexing for $1 \mathrm{~min}$, followed by the addition of $600 \mu \mathrm{L}$ acetonitrile. Diluted samples were mixed by vortexing for $1 \mathrm{~min}$, centrifuged at 3,000 rpm for $3 \mathrm{~min}$, and the resulting supernatant was transferred to a clean 96-well plate. Samples were dried under nitrogen in the Turbovap, and then reconstituted with $300 \mu \mathrm{L}$ of $0.1 \%$ formic acid in $20 \%$ acetonitrile in aqueous solution. To produce the standard curve, the plasma samples from untreated mice were spiked with known amounts of NAX 5055. Samples were separated by reversed-phase HPLC (Shimadzu SCL-10A controller with LC-10AD pump; Shimadzu Scientific Instruments, Columbia, MD), using a $\mathrm{C}_{18}$ column (Varian Metasil, AQ C18, $50 \times 2 \mathrm{~mm}$; Varian, Inc, Palo Alto, CA), a linear gradient of acetonitrile in $0.2 \%$ formic acid and a flow rate of $0.5 \mathrm{~mL} / \mathrm{min}$. The separations were monitored by electrospray ionization mass spectrometry (API 5000) in the positive ion ionization mode. The standard curve was linear within the range of $12.5 \mathrm{ng} / \mathrm{mL}$ to $20,000 \mathrm{ng} / \mathrm{mL}$.

\section{RESULTS}

\section{Anticonvulsant profile}

The results obtained with NAX 5055 in a battery of well-established anticonvulsant tests are summarized in

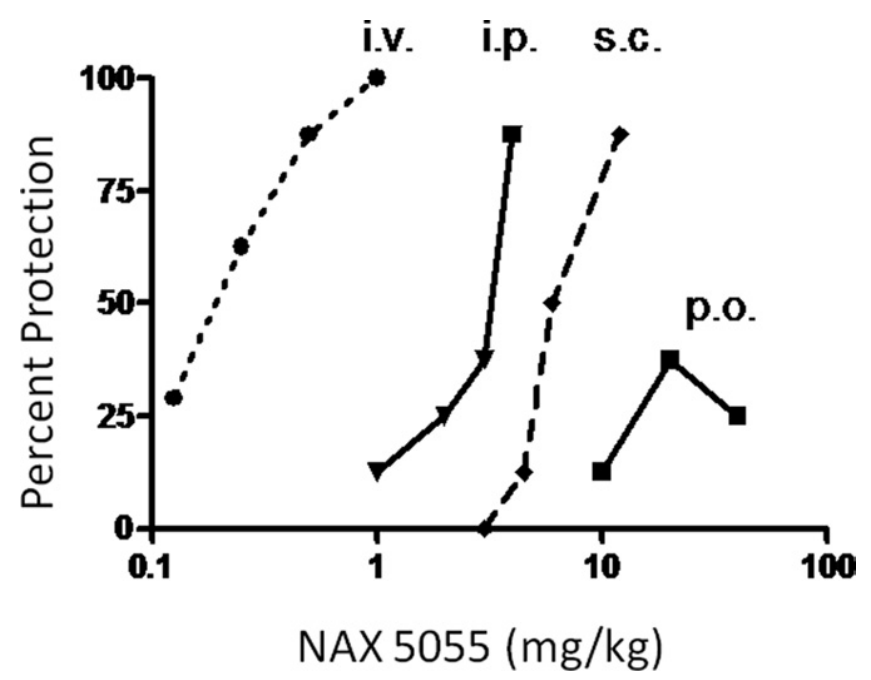

FIG. 3. Bioavailability of NAX 5055 after several routes of systemic administration. NAX 5055 was administered intravenously (i.v.), intraperitoneally (i.p.), subcutaneously (s.c.), and orally (p.o.) in CF-1 mice. Dose-response data were generated at the following time points for each route of administration $1 \mathrm{~h}$ (i.v., i.p., and s.c.) and $2 \mathrm{hr}$ (p.o.). 
Table 2. Comparative Anticonvulsant Activity of NAX 5055 and Several Control Analogs (e.g. Gal[1-16], "Scrambled" and "Truncated") in the $6 \mathrm{~Hz}(32 \mathrm{~mA})$ Model of Epilepsy in CF-1 Mice

\begin{tabular}{|c|c|c|c|c|c|c|}
\hline \multirow[b]{2}{*}{ Analog } & \multirow[b]{2}{*}{ Structure } & \multicolumn{5}{|c|}{ Dose (4 mg/kg, i.p.) } \\
\hline & & $15^{\prime}$ & $30^{\prime}$ & $60^{\prime}$ & $120^{\prime}$ & $240^{\prime}$ \\
\hline Galanin $(1-16)^{*}$ & GWTLNSAGYLLGPHAV-NH ${ }_{2}$ & $0 / 4$ & $0 / 4$ & $0 / 4$ & $0 / 4$ & $0 / 4$ \\
\hline NAX 5055* & (Sar)WTLNSAGYLLGPKK(Lys-P)K & $3 / 4$ & $4 / 4$ & $4 / 4$ & $4 / 4$ & $0 / 4$ \\
\hline NAX 5055 scrambled & (Sar)YTLLSAGWLLGPKK(Lys-P)K & $0 / 4$ & $0 / 4$ & $0 / 4$ & $0 / 4$ & $0 / 4$ \\
\hline NAX 5055 truncated & Ac-YLLGPKK(Lys-P)K & $0 / 4$ & $0 / 4$ & $0 / 4$ & $0 / 4$ & $1 / 4$ \\
\hline
\end{tabular}

Values shown represent a number of mice protected from seizures in groups of four mice per time point. Note that Trp2, Asn5, and Tyr9 are critical residues for binding to the galanin receptors. Any modifications or replacement of these amino acid residues results in a loss of the affinity to the galanin receptors. ${ }^{42,43} \mathrm{Sar}=$ sarcosine; Lys-P $=$ lipo-amino acid; Lysine $=$ palmitoyl.

*Values reported previously from Bulaj et al, ${ }^{17} 2008$.

Table 1 and FIGs. 2 and 3. The anticonvulsant activity of NAX 5055 was initially defined in the Frings AGSsusceptible mouse model of reflex epilepsy after i.p. administration of $4 \mathrm{mg} / \mathrm{kg}$. At various times after i.p. administration, each mouse was placed into a cylindrical test chamber fitted with an audio transducer and challenged with a high-intensity sound stimulus. The results obtained from this study demonstrate that NAX 5055 displays a time-dependent anticonvulsant effect with a time-to-peak effect of $1 \mathrm{~h}$. The $\mathrm{ED}_{50}$ for protection against sound-induced seizures was determined to be 3.2 $\mathrm{mg} / \mathrm{kg}$, i.p. (Table 1).

After i.p. administration, NAX 5055 was found to be highly potent against acute psychomotor seizures induced by $6 \mathrm{~Hz}$ corneal stimulation, regardless of the stimulus intensity used (FIG. 2). For example, $\mathrm{ED}_{50} \mathrm{~s}$ determined at the i.p. time-to-peak effect against $6 \mathrm{~Hz}$ seizures induced at 22,32 , and $44 \mathrm{~mA}$ were $0.7,0.8$, and $2.9 \mathrm{mg} / \mathrm{kg}$, respectively.

NAX 5055 was also extremely potent against the fully expressed secondarily generalized seizure in the mouse corneal kindling model of partial seizures $\left(\mathrm{ED}_{50}\right.$ : 0.65 $\mathrm{mg} / \mathrm{kg}$; Table 1). In this test, NAX 5055 reduced the seizure severity from an average Racine score of 5 to $<$ 1 at the highest dose evaluated (i.e., $6 \mathrm{mg} / \mathrm{kg}$, i.p.).

In an effort to determine the relative bioavailability of NAX 5055, it was administered by i.v., i.p., s.c., and p.o. routes in the $32 \mathrm{~mA} 6 \mathrm{~Hz}$ seizure model. The rank order of potency was i.v. $>$ i.p. $>$ s.c. $>$ p.o. (FIG. 3). When compared with the i.p. route, NAX 5055 was approximately 7 times more potent after i.v. administration and approximately 3 -fold less potent after s.c. administration $\left(\mathrm{ED}_{50} \mathrm{~s}: 0.25,1.8\right.$, and $7.8 \mathrm{mg} / \mathrm{kg}$, respectively). NAX 5055 was not fully efficacious after p.o. administration. As shown in FIG. 3, a maximum of $37.5 \%$ protection was observed at a dose of $20 \mathrm{mg} / \mathrm{kg}$, p.o. Moreover, increasing the dose to $40 \mathrm{mg} / \mathrm{kg}$, p.o. resulted in a slightly lower level of protection $(25 \%)$.

In contrast to the modified galanin-based analog NAX 5055 , the unmodified native peptide galanin (1-16) was inactive at a dose of $4 \mathrm{mg} / \mathrm{kg}$, i.p. when tested at a current intensity of $32 \mathrm{~mA}$ (Table 2). Previously we have demonstrated that the native peptide fragment was active when it was administered directly to the brain via intracerebroventricular administration. ${ }^{17}$ Two NAX 5055 analogs, scrambled and truncated, were also inactive in this model when tested across time at a dose of $4 \mathrm{mg} / \mathrm{kg}$, i.p. (Table 2). These two analogs had critical residues for the galanin receptor binding either exchanged (NAX 5055 scrambled) or removed (NAX 5055 truncated). Collectively, these results suggest that anticonvulsant activity of NAX 5055 is dependent on penetration of the BBB and selectivity for the target GalR1 receptor.

\section{Pharmacokinetics}

To assess the pharmacokinetic profile of NAX 5055, plasma levels of the galanin analog were determined in mice at different time points after bolus i.p. administration. As illustrated in FIG. 4A, detectable plasma levels of NAX 5055 were observed after 15 min post-drug administration $(2 \mathrm{mg} / \mathrm{kg})$ and peaked at 1 hour. Based on a time course of disappearance of NAX 5055, the halflife was estimated to be 120 minutes. As shown in FIG. $4 \mathrm{~B}$, the time-dependent protection against seizures in the $32 \mathrm{~mA} 6 \mathrm{~Hz}$ model was correlated with NAX 5055 plasma levels. In addition, NAX 5055 displayed linear pharmacokinetics between $0.1 \mathrm{mg} / \mathrm{kg}$ to $4 \mathrm{mg} / \mathrm{kg}$. Full protection of animals from seizures was obtained with plasma levels of $4,500 \mathrm{ng} / \mathrm{mL}$.

\section{DISCUSSION}

The goal of the present study was to extend the pharmacological profile of NAX 5055 in epilepsy models. We previously showed that NAX 5055 was active in the $32 \mathrm{~mA} 6 \mathrm{~Hz}$ model of refractory epilepsy. ${ }^{17}$ The present study demonstrated that NAX 5055 retained its potency in the $6 \mathrm{~Hz}$ test across all stimulation intensities $(22 \mathrm{~mA}$ to $44 \mathrm{~mA}$ ). The $\mathrm{ED}_{50}$ value at each stimulation intensity was well below the dose producing motor impairment in mice. These results are in contrast with those for several other marketed AEDs which show a significant loss of 

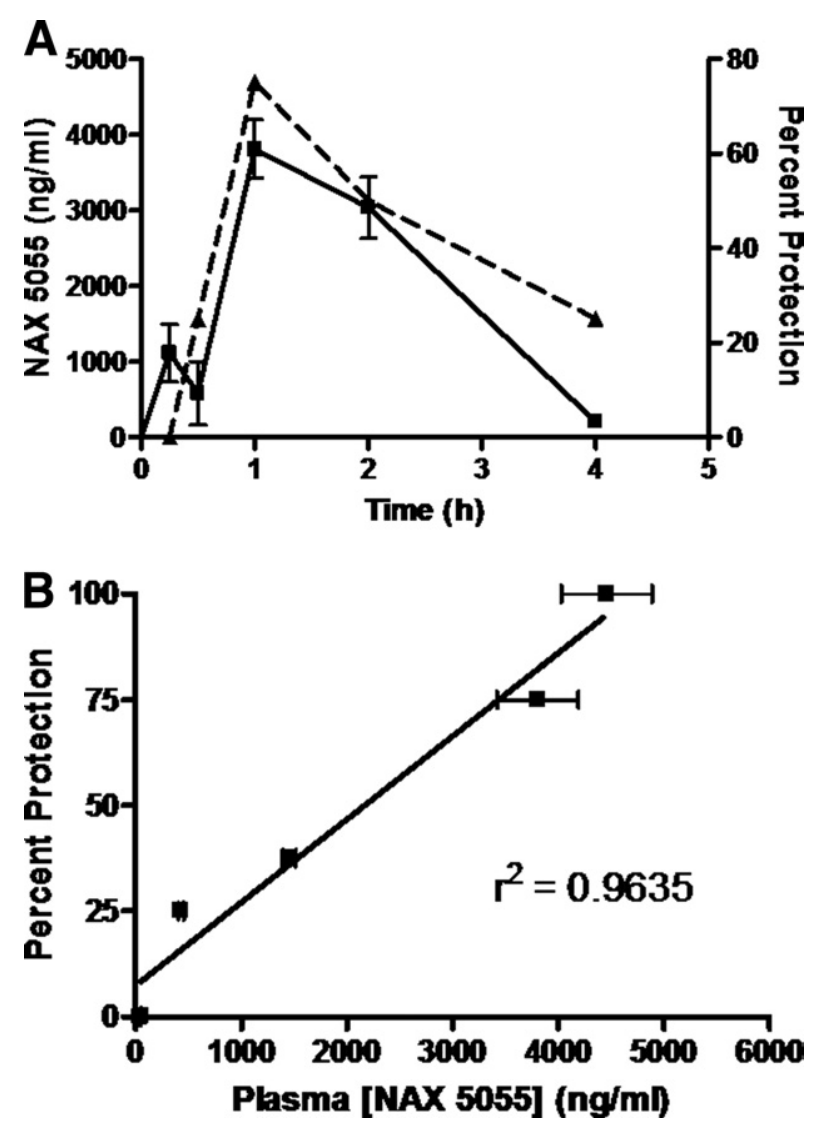

FIG. 4. Pharmacokinetic analysis of NAX 5055 in CF-1 mice. A: time-dependent changes of NAX 5055 (solid line) after a bolus intraperitoneal administration of $2 \mathrm{mg} / \mathrm{kg}$ dose. Dash line represents a time response of NAX 5055 at the same dose in protecting mice from seizures in the $6 \mathrm{~Hz}(32 \mathrm{~mA})$ seizure model. B: A linear correlation between plasma levels of NAX 5055 and percent of seizure protection at doses $0.1,0.25,0.5,2$, and $4 \mathrm{mg} / \mathrm{kg}$. Plasma levels were determined at $1 \mathrm{~h}$ after the administration of NAX 5055.

potency or become inactive in the $6 \mathrm{~Hz}$ test at higher stimulation intensities (Table 3). In addition to the $6 \mathrm{~Hz}$ model, NAX 5055 was found to be a potent blocker of secondarily generalized seizures in the corneal kindled mouse. NAX 5055 was also effective in controlling sound-induced motor seizures in Frings audiogenic mice. However, NAX 5055 was not active in the mouse maximal electroshock test and was only minimally active in the s.c. PTZ at high dose. We previously showed that NAX 5055 binds the GalR1 and GalR2 receptors, ${ }^{17}$ and the antiepileptic effects for NAX 5055 observed in this study do not appear to be mediated by the chemical modifications to the analog. Neither the scrambled nor truncated peptides showed antiepileptic activity when evaluated in the $6 \mathrm{~Hz}$ test.

These study results revealed that NAX 5055 was active after several routes of systemic administration (i.v., i.p., s.c. and p.o.) and possesses predictable pharmacokinetic properties. It was most potent with i.v. administration and only weakly active after oral administration.
One hour after i.p. administration there was a linear correlation between antiepileptic activity and measured plasma concentration. The time-course of activity in the $6 \mathrm{~Hz}$ test also tracked closely with measured plasma levels of the compound. Behavioral activity was apparent at 15 minutes with measurable plasma levels and declined after 2 hours, which is near the half-time for measured plasma levels.

Galanin and its receptors have been validated as antiepileptic therapeutic targets using genetic and pharmacological tools. ${ }^{27-29}$ Galanin immunoreactivity in the hippocampus is highest in the dentate gyrus, which receives excitatory innervations from the entorhinal cortex. The entorhinal cortex-dentate gyrus fiber tract is also known as the perforant pathway, which can be stimulated to evoke seizure activity. ${ }^{30}$ The Gal-R1 and Gal-R2 subtypes are both expressed in the hippocampus and are believed to contribute to different components of seizure generation and epileptogenesis. ${ }^{31}$ There is obviously great therapeutic potential in the targeting of these two receptors. Compounds active at the galanin receptors that also penetrate the BBB have been previously synthesized. Galnon and galmic are nonpeptide small molecules, and both can be administered systemically to inhibit seizures in animal models of PTZ-stimulated and perforant path-stimulated seizures. ${ }^{32,33}$ However, these compounds have had limited value due to low binding affinity and the lack of receptor subtype discrimination. Our efforts have instead been directed toward making a galanin peptide analog that not only can penetrate the $\mathrm{BBB}$ and remain metabolically stable, but can also retain nanomolar affinity. We have shown that by using a combination of lipidization and cationization on the galanin backbone, these goals can be achieved. ${ }^{17}$ Furthermore, we have been able to engineer GalR1 or GalR2 selectivity into these galanin analogs. In this article we demonstrate the functionality of one compound, NAX 5055, in halting the seizure activity in particular forms of evoked seizures.

As previously summarized, NAX 5055 is not active in the maximal electroshock and subcutaneous PTZ tests. In this regard, the anticonvulsant profile of NAX 5055 is very much like that of the SV2a modulator levetiracetam, which is also inactive in these two acute seizure models. ${ }^{34,35}$ It is also important to note that NAX 5055, unlike the two previously described small molecule galanin agonists (galnon and galmic), is not effective against PTZ-induced seizures. This apparent discrepancy in anticonvulsant profile is likely due to the low $\mu \mathrm{M}$ affinity of galnon and galmic for galanin receptors and their reported off-target actions. For example, at $10 \mu \mathrm{M}$, both galnon and galmic interact with a variety of nongalanin receptors, including 5-HT-1A and 5-HT-1B receptors, D2 dopamine receptors, ghrelin and melanocortin receptors, NPY receptors (galnon only), or $\mu$-opioid re- 
Table 3. Anticonvuslant Profile of NAX 5055 Compared with Other Antiepileptic Drugs in the $6 \mathrm{~Hz}$ Model

\begin{tabular}{|c|c|c|c|}
\hline \multirow[b]{3}{*}{ AED } & \multicolumn{3}{|c|}{$\mathrm{ED}_{50}, \mathrm{mg} / \mathrm{kg}$, i.p. (95\% confidence interval) } \\
\hline & \multicolumn{3}{|c|}{ Stimulation Intensity } \\
\hline & $22 \mathrm{~mA}$ & $32 \mathrm{~mA}$ & $44 \mathrm{~mA}$ \\
\hline \multirow[t]{2}{*}{ NAX 5055} & $0.7(0.4-1.2)$ & $0.8(0.4-1.6)$ & $2.9(1.9-4.3)$ \\
\hline & $\mathrm{PI}^{*}=30$ & $\mathrm{PI}=26.3$ & $\mathrm{PI}=7.2$ \\
\hline \multirow[t]{2}{*}{ Valproic acid $^{\dagger}$} & $41.5(16.1-68.8)$ & $126(94.5-152)$ & $310(258-335)$ \\
\hline & $\mathrm{PI}=11.6$ & $\mathrm{PI}=3.8$ & $\mathrm{PI}=1.6$ \\
\hline \multirow[t]{2}{*}{ Leviteracitam $^{\dagger}$} & $4.6(1.1-8.7)$ & $19.4(9.9-36.0)$ & $1089(787-2650)$ \\
\hline & $\mathrm{PI}>217$ & $\mathrm{PI}>51$ & $\mathrm{PI} \geq 1$ \\
\hline \multirow[t]{2}{*}{ Ethosuximide $^{\dagger}$} & $86.9(37.8-156)$ & $167(114-223)$ & $>600$ \\
\hline & $\mathrm{PI}=3.7$ & $\mathrm{PI}=1.9$ & $\mathrm{PI}<0.6$ \\
\hline \multirow[t]{2}{*}{ Phenytoin $^{\dagger}$} & $9.4(4.7-14.9)$ & $>60$ & $>60$ \\
\hline & $\mathrm{PI}=4.6$ & $\mathrm{PI}<0.7$ & $\mathrm{PI}<0.7$ \\
\hline \multirow[t]{2}{*}{ Lamotrigine $^{\dagger}$} & $4.4(2.2-6.6)$ & $>60$ & $>60$ \\
\hline & $\mathrm{PI}=6.8$ & $\mathrm{PI}<0.5$ & $\mathrm{PI}<0.5$ \\
\hline \multirow[t]{2}{*}{ Lacosamide $^{\ddagger}$} & - & $9.9(7.7-12.8)$ & - \\
\hline & & $\mathrm{PI}=2.7$ & \\
\hline
\end{tabular}

$\mathrm{AED}=$ antiepileptic drug; i.p. $=$ intraperitoneal injection; $\mathrm{PI}=$ protective index

*Toxic dose 50 value for motor impairment/ED 50 value.

${ }^{\dagger}$ Barton et al., 2001. ${ }^{19}$

${ }^{\ddagger}$ Stöhr et al., $2007 .{ }^{44}$

ceptors (galmic only). Activities at one or more of these nongalanergic targets likely contribute to their efficacy in the PTZ test. Thus, the primary limitation of these first generation galanin agonists is that they are both nonselective, low affinity molecules that can interact with other pharmacological targets. ${ }^{16}$ In this respect, high affinity and receptor selectivity of NAX 5055 for galanin receptors provides two distinct advantages in comparison with currently available galanin agonists for dissecting the role of galanin receptors in epilepsy and other CNS disorders.

In the present investigation, NAX 5055 was uniquely active in the $6 \mathrm{~Hz}$ psychomotor seizure test. Interestingly, the pharmacological profile of the $6 \mathrm{~Hz}$ model is somewhat dependent on the intensity of the stimulation (Table 3). For example, a convulsive current (CC) of 22 $\mathrm{mA}$ is sufficient to induce a prototypical seizure in $97 \%$ of the population tested (i.e., the $\mathrm{CC}_{97}$ ), the $6 \mathrm{~Hz}$ seizure test is relatively nondiscriminating (that is, the large majority of AEDs evaluated (phenytoin, lamotrigine, ethosuximide, levetiracetam, and valproic acid) and are effective in blocking the acute seizure. As the current intensity is increased to a level that is 1.5 times the $\mathrm{CC}_{97}$ (32 mA), several of the AEDs lose their ability to protect against a $6 \mathrm{~Hz}$ seizure. At a current equivalent to two times the $\mathrm{CC}_{97}$ (i.e., $44 \mathrm{~mA}$ ), only valproic acid and levetiracetam retained their ability to block $6 \mathrm{~Hz}$ seizures; albeit, the potency of both drugs at two times the $\mathrm{CC}_{97}$ was markedly reduced. Given the pharmacological profile of this model, it has evolved as a unique model for differentiating the potential anticonvulsant compounds that might be useful for the treatment of refractory partial epilepsy. In this regard, the results obtained in this study suggest that NAX 5055 may provide some advantages over other available AEDs. Among the various AEDs that have been evaluated in the $6 \mathrm{~Hz}$ model, NAX 5055 is extremely potent after i.p. administration (Table 3). Moreover, it retained excellent efficacy at all three stimulus currents evaluated. Unlike the sodium channel blockers phenytoin, carbamazepine, and lamotrigine, the SV2A modulator levetiracetam and the broad-spectrum AED valproic acid, the potency of NAX 5055 was largely retained as the stimulus intensity was increased from 22 to $44 \mathrm{~mA}$. It is also of interest to note that among the various AEDs evaluated in this model, NAX 5055 was the most potent at all three stimulus intensities.

NAX 5055 was also shown to be highly efficacious and potent in a rodent model believed to mimic temporal lobe epilepsy, the most common type of epilepsy in adult humans. ${ }^{36,37}$ The pharmacology of the corneal kindled mouse model is very consistent with that observed in more traditional electrical kindling models, such as the hippocampal kindled rat (Rowley et al., manuscript in preparation). For example, lamotrigine, carbamazepine, and valproic acid are all active in this model at doses of $9.9,33$, and $121 \mathrm{mg} / \mathrm{kg}$, i.p. Phenytoin is not active at doses that produce marked motor impairment (i.e., $>50$ $\mathrm{mg} / \mathrm{kg}$, i.p.). NAX 5055 decreased the seizure severity in a dose-dependent manner at doses well below those that produced behavioral toxicity $\left(\mathrm{ED}_{50} ; 0.65 \mathrm{mg} / \mathrm{kg}\right.$, i.p.). Thus, NAX 5055 is at least one order of magnitude more potent in this model than several of the established AEDs. It is also important to note that activity of NAX 5055 in the corneal kindled mouse is an activity that it 
shares with the SV2A modulator levetiracetam. ${ }^{20}$ This finding further supports the potential therapeutic use of galanin-based therapeutics for the symptomatic treatment of partial epilepsy.

Because galanin plays a role in pleiotropic neurological functions, including seizure control, epileptogenesis, antinociception, neuroprotection, and neurotrophic activities, NAX 5055 represents a drug prototype that may have broad clinical applications. First, the potent antiepileptic activity of NAX 5055 in the pharmacoresistant model of epilepsy makes this class of analogs drug candidates for treatment of refractory seizures. As a potential first-in-class therapeutic, NAX 5055 or its analogs will have to be carefully evaluated for their long-term toxicity, safety, and tolerance before entering the clinical development stage. Antiepileptogenic and neuroprotective actions of galanin may also be retained in NAX 5055 , but more studies are needed to evaluate these beneficial aspects of galanin-based antiepileptic therapy. Second, GalR1 and GalR2 selective agonists also display anxiolytic activity, thus applications of NAX 5055 may extend to controlling anxiety and modulating mood disorders. ${ }^{38}$ Third, the potential of NAX 5055 as an analgesic is also apparent: numerous studies have demonstrated a role of galanin in neuropathic pain. ${ }^{39-41}$ Our results indeed suggest that NAX 5055 is an effective analgesic in various animal pain models (Adkins-Scholl et al, manuscript in preparation). Given the broad spectrum bioavailability of NAX 5055, various routes of administration (ranging from subcutaneous depo-formulations to a rapid intranasal delivery) may facilitate multiple clinical applications. Current efforts of our research group are focused on selecting optimal therapeutic indications for NAX 5055 analogs to enter clinical development.

\section{Disclosure}

G. B. and H. S. W. are scientific co-founders of NeuroAdjuvants, Inc.

Acknowledgments: This work was supported in part by the Epilepsy Therapy Grants Program from the Epilepsy Research Foundation, the University of Utah Startup Funds, the University of Utah Research Foundation, and NIH grant R21 NS059669 (GB and HSW). We thank the Anticonvulsant Screening Program (ASP) Project Officer, James Stables, and his group at the National Institutes of Health, National Institute of Neurological Disorders and Stroke for their support of the galanin project. We also thank Dan McDougle for his help with purification of the galanin analogs.

\section{REFERENCES}

1. Baraban SC, Tallent MK. Interneuron diversity series: interneuronal neuropeptides-endogenous regulators of neuronal excitability. Trends Neurosci 2004;27:135-142.

2. Hokfelt T, Broberger C, Xu ZQ, Sergeyev V, Ubink R, Diez M. Neuropeptides-an overview. Neuropharmacology 2000;39:13371356.
3. Waxham N. Neuropeptides and nitric oxide. In: Byrne JH, ed. Neuroscience Online, 2007. Available at: http://neuroscience. uth.tmc.edu. Accessed July 15, 2007.

4. Gundlach AL, Jungnickel R-F. Galanin and GALP systems in brain - molecular pharmacology, anatomy, and putative roles in physiology and pathology. In: Kastin AJ, ed. Handbook of biologically active peptides. Amsterdam: Elsevier, 2006:753-761.

5. Hawes JJ, Picciotto MR. Characterization of GalR1, GalR2, and GalR3 immunoreactivity in catecholaminergic nuclei of the mouse brain. J Comp Neurol 2004;479:410-423.

6. Gorter JA, van Vliet EA, Aronica E, et al. Potential new antiepileptogenic targets indicated by microarray analysis in a rat model for temporal lobe epilepsy. J Neurosci 2006;26:11083-11110.

7. Mazarati AM, Halaszi E, Telegdy G. Anticonvulsive effects of galanin administered into the central nervous system upon the picrotoxin-kindled seizure syndrome in rats. Brain Res 1992;589: $164-166$.

8. Gu XL, Sun YG, Yu LC. Involvement of galanin in nociceptive regulation in the arcuate nucleus of hypothalamus in rats with mononeuropathy. Behav Brain Res 2007;179:331-335.

9. Kanter-Schlifke I, Toft Sørensen A, Ledri M, Kuteeva E, Hökfelt $\mathrm{T}$, Kokaia M. Galanin gene transfer curtails generalized seizures in kindled rats without altering hippocampal synaptic plasticity. Neuroscience 2007;150:984-992.

10. Wynick D, Bacon A. Targeted disruption of galanin: new insights from knock-out studies. Neuropeptides 2002;36:132-144.

11. Kokaia M, Holmberg K, Nanobashvili A, et al. Suppressed kindling epileptogenesis in mice with ectopic overexpression of galanin. Proc Natl Acad Sci U S A 2001;98:14006-14011.

12. Liu HX, Brumovsky P, Schmidt R, et al. Receptor subtype-specific pronociceptive and analgesic actions of galanin in the spinal cord: selective actions via GalR1 and GalR2 receptors. Proc Natl Acad Sci U S A 2001;98:9960-9964.

13. Mahoney SA, Hosking R, Farrant S, et al. The second galanin receptor GalR2 plays a key role in neurite outgrowth from adult sensory neurons. J Neurosci 2003;23:416-421.

14. Branchek TA, Smith KE, Gerald C, Walker MW. Galanin receptor subtypes. Trends Pharmacol Sci 2000;21:109-117.

15. Lundstrom L, Elmquist A, Bartfai T, Langel U. Galanin and its receptors in neurological disorders. Neuromolecular Med 2005;7: $157-180$.

16. Lu X, Lundstrom L, Langel U, Bartfai T. Galanin receptor ligands. Neuropeptides 2005;39:143-146.

17. Bulaj G, Green BR, Lee H-K, et al. Design, synthesis and characterization of high-affinity, systemically-active galanin analogs with potent anticonvulsant activities. J Med Chem 2008;51:8038-8047.

18. White HS, Watson WP, Hansen SL, et al. First demonstration of a functional role for central nervous system betaine/ $\{$ gamma $\}$-aminobutyric acid transporter (mGAT2) based on synergistic anticonvulsant action among inhibitors of mGAT1 and mGAT2. J Pharmacol Exp Ther 2005;312:866-874.

19. Barton ME, Klein BD, Wolf HH, White HS. Pharmacological characterization of the $6 \mathrm{~Hz}$ psychomotor seizure model of partial epilepsy. Epilepsy Res 2001;47:217-227.

20. Matagne A, Klitgaard $H$. Validation of corneally kindled mice: a sensitive screening model for partial epilepsy in man. Epilepsy Res 1998;31:59-71.

21. Woodbury LA, Davenport VD. Design and use of a new electroshock seizure apparatus, and analysis of factors altering seizure threshold and pattern. Arch Int Pharmacodyn Ther 1952;92:97-104.

22. Brown WC, Schiffman DO, Swinyard EA, Goodman LS. Comparative assay of antiepileptic drugs by "psychomotor" seizure test and minimal electroshock threshold test. J Pharmacol Exp Ther 1953;107:273-283.

23. Matagne A, Klitgaard $\mathrm{H}$. Validation of corneally kindled mice: a sensitive screening model for partial epilepsy in man. Epilepsy Res Suppl 1998;31:59-71.

24. Racine RJ. Modification of seizure activity by electrical stimulation. II. Motor seizure. Electroencephalogr Clin Neurophysiol 1972;32:281-294.

25. Dunham MS, Miya TA. A note on a simple apparatus for detecting neurological deficit in rats and mice. J Amer Pharm Ass Sci Ed 1957;46:208-209. 
26. Finney DJ. Probit Analysis, 3rd ed. London: Cambridge University Press, 1971.

27. Lang R, Gundlach AL, Kofler B. The galanin peptide family: receptor pharmacology, pleiotropic biological actions, and implications in health and disease. Pharmacol Ther 2007;115:177-207.

28. Lerner JT, Sankar R, Mazarati AM. Galanin and epilepsy. Cell Mol Life Sci 2008;65:1864-1871.

29. Mitsukawa K, Lu X, Bartfai T. Galanin, galanin receptors and drug targets. Cell Mol Life Sci 2008;65:1796-1805.

30. Heinemann U, Schmitz D, Eder C, Gloveli T. Properties of entorhinal cortex projection cells to the hippocampal formation. Ann N Y Acad Sci 2000;911:112-126.

31. Mazarati A, Lundstrom L, Sollenberg U, Shin D, Langel U, Sankar R. Regulation of kindling epileptogenesis by hippocampal galanin type 1 and type 2 receptors: The effects of subtype-selective agonists and the role of G-protein-mediated signaling. J Pharmacol Exp Ther 2006;318:700-708.

32. Bartfai T, Lu X, Badie-Mahdavi H, et al. Galmic, a nonpeptide galanin receptor agonist, affects behaviors in seizure, pain, and forced-swim tests. Proc Natl Acad Sci U S A 2004;101:1047010475.

33. Saar K, Mazarati AM, Mahlapuu R, et al. Anticonvulsant activity of a nonpeptide galanin receptor agonist. Proc Natl Acad Sci U S A 2002;99:7136-7141.

34. Klitgaard H, Matagne A, Gobert J, Wulfert E. Evidence for a unique profile of levetiracetam in rodent models of seizures and epilepsy. Eur J Pharmacol 1998;353:191-206.

35. Loscher W, Honack D. Profile of ucb L059, a novel anticonvulsant drug, in models of partial and generalized epilepsy in mice and rats. Eur J Pharmacol 1993;232:147-158.

36. Loscher W. Animal models of epilepsy for the development of antiepileptogenic and disease-modifying drugs. A comparison of the phar- macology of kindling and post-status epilepticus models of temporal lobe epilepsy. Epilepsy Res 2002;50:105-123.

37. Stables JP, Bertram EH, White HS, et al. Models for epilepsy and epileptogenesis: report from the NIH workshop, Bethesda, Maryland. Epilepsia 2002;43:1410-1420.

38. Wrenn CC, Holmes A. The role of galanin in modulating stressrelated neural pathways. Drug news \& perspectives 2006;19:461467.

39. Hygge-Blakeman K, Brumovsky P, Hao JX, et al. Galanin overexpression decreases the development of neuropathic pain-like behaviors in mice after partial sciatic nerve injury. Brain research 2004;1025:152-158.

40. Liu H, Hokfelt T. Effect of intrathecal galanin and its putative antagonist M35 on pain behavior in a neuropathic pain model. Brain research 2000;886:67-72.

41. Wiesenfeld-Hallin Z, Xu XJ, Langel U, Bedecs K, Hokfelt T, Bartfai T. Galanin-mediated control of pain: enhanced role after nerve injury. Proceedings of the National Academy of Sciences of the United States of America 1992;89:3334-3337.

42. Fisone G, Berthold M, Bedecs K, et al. N-terminal galanin-(1-16) fragment is an agonist at the hippocampal galanin receptor. Proceedings of the National Academy of Sciences of the United States of America 1989;86:9588-9591.

43. Land T, Langel U, Low M, Berthold M, Unden A, Bartfai T. Linear and cyclic N-terminal galanin fragments and analogs as ligands at the hypothalamic galanin receptor. International journal of peptide and protein research 1991;38:267-272.

44. Stohr T, Kupferberg HJ, Stables JP, et al. Lacosamide, a novel anti-convulsant drug, shows efficacy with a wide safety margin in rodent models for epilepsy. Epilepsy research 2007;74:147154. 